\title{
POTENCIALIDADES DO PARQUE DA CIDADE EM SERRA-ES PARA O ENSINO DE BOTÂNICA: UMA PROPOSTA DE SEQUÊNCIA DIDÁTICA
}

\section{BIANCA AMBROZINI CAMARGO}

Instituto Federal do Espírito Santo - Ifes

E-mail: biambrozini@gmail.com

\section{MARINA CADETE DA PENHA}

Instituto Federal do Espírito Santo - Ifes

E-mail: marina_cadete@hotmail.com

\begin{abstract}
RESUMO
Visando a elaborar uma sequência didática que evidencie o potencial educativo do Parque da Cidade em Serra - ES, para o ensino de botânica, por meio de vivências educativas que perpassam pelos espaços de educação formal e não formal este trabalho foi desenvolvido. Tratou-se de uma pesquisa de cunho qualitativo, do tipo estudo de caso. A pesquisa foi dividida em três etapas: a primeira etapa foi levantar o potencial educativo do Parque da Cidade para o ensino de botânica na educação básica, na perspectiva da educação formal e não formal; a segunda foi elaborar uma sequência didática sobre o tema Botânica, por meio de vivências educativas que perpassam pelos espaços de educação formal e não formal; e a terceira foi validar a priori a sequência didática junto a pares. A validação a priori foi realizada por oito professores, de diferentes disciplinas da educação básica. Espera-se que a sequência didática possa contribuir para a melhoria da dinâmica das aulas de botânica, motivando o professor quanto às formas diferenciadas de explanação desse conteúdo em sala de aula e que os alunos compreendam o conteúdo de forma mais eficaz, assimilando-o com mais facilidade e associando-o ao seu dia a dia.
\end{abstract}

\section{PalaVRas-ChaVe:}

Ensino de Botânica; Educação Não-formal; Sequência Didática.

POTENTIALITIES OF THE SERRA CITY PARK FOR THE TEACHING OF BOTANY: A PROPOSAL FOR A DIDACTIC SEQUENCE

\begin{abstract}
With the object of elaborating a didactic sequence that shows the educational potential of the Parque da Cidade (Park of the City) in Serra - ES, for the teaching of botany, by experiences of education through the formal and non-formal spaces of education was developed. It was a qualitative research, of the type of study of case. The research was divided into three stages: The first step was to raise the potential of the Parque da Cidade for the teaching of botany in basic education, at perspective of formal and nonformal education. The second was to elaborate a sequence didactic about Botany, through educational experiences that permeate the formal and non-formal spaces of education; and the third was to validate priority the sequence didactic with pairs. The validation was performed by eight teachers of different disciplines of basic education. It is expected that the didactic sequence may contribute to improving the dynamics of botany classes, motivating the teacher differentiated
\end{abstract}


forms of explanation of this content in the classroom and that students understand content more effectively, assimilating it easily and associating it with your daily routine.

\section{KEYWORDS:}

Botany Teaching; Non-formal education; Sequence didactic.

\section{INTRODUÇÃO}

Durante os anos que a pesquisadora atuou como monitora, e hoje como professora (atuando no ensino fundamental II da rede privada, em um pré-vestibular para medicina e no PROEJA, do Ifes - campus Vitória), pôde observar que, a maioria dos alunos apresenta baixa afinidade e receio quanto às disciplinas que envolvam Biologia Vegetal, o que segundo pesquisadores da área se deve a variados fatores.

No ensino de botânica, quando o conteúdo é somente descritivo, se torna complexo, isto é, sua compreensão torna-se mais complexa, causando total desinteresse na maior parte dos alunos (PINTO, 2009), o que metaforicamente Freire (1987) nomeia como "educação bancária".

Nessa perspectiva, Freire (1987) faz uma crítica a escola, em qualquer de seus níveis, como também fora dela, que apresenta uma relação educador-educando fundamentalmente narradora, comparando o narrar dos conteúdos a uma enfermidade, que produz algo quase morto, algo parado, compartimentado e bemcomportado (DIAS, 2014. p.39).

O enfoque tradicional e sistemático com que os professores vêm trabalhando a botânica, reflete na baixa rentabilidade dos alunos nesse conteúdo, ou seja, o assunto deve ser trabalhado de forma diversificada para que os alunos tenham interesse em aprender botânica (KRASILCHICK; TRIVELATO, 1995).

De acordo com Arruda e Laburú (1996), a aquisição do conhecimento em botânica é prejudicada não somente pela falta de estímulos em observar e interagir 
com as plantas, como também pela precariedade de equipamentos, métodos e tecnologias que possam ajudar no aprendizado.

Além disso, a observação e interação dos alunos são de extrema importância, pois para aprender deve se ver e observar para então entender o que vem a ser aquilo que está sendo visto (FERRAZ; FUSARI, 1993).

Em 2017, a partir do ingresso no curso de pós-graduação em Educação e Divulgação em Ciências do Ifes - Vila Velha, surge a motivação para a presente pesquisa, que parte de questionamentos quanto ao ensino de botânica levantados a partir da experiência da pesquisadora, como monitora durante a graduação e hoje como professora, unindo as experiências vividas no EDIV, onde a mesma pôde aprofundar e vivenciar o conhecimento quanto a Sequências Didáticas (SD) e a Espaços de Educação não Formal (EENF).

Desse modo, o objetivo geral foi elaborar e validar uma sequência didática que evidencie o potencial educativo do Parque da Cidade em Serra - ES, para o ensino de botânica, por meio de vivências educativas que perpassam pelos espaços de educação formal e não formal.

O Parque da Cidade foi escolhido, pois trata-se de um local com diversos espaços e possibilidades educativas. A presença de ambientes como: bromeliário, orquidário, jardim sensorial e os diversos tipos de plantas encontradas por toda a extensão do parque, proporcionam várias opções de temas que podem ser abordados dentro do conteúdo da biologia vegetal. Sendo assim, acredita-se que seja de grande importância o levantamento das potencialidades para o ensino de Botânica, neste local.

Para alcançar o objetivo geral, este estudo possui os seguintes objetivos específicos: 
- Levantar o potencial educativo do Parque da Cidade para o ensino de botânica na educação básica, na perspectiva da educação formal e não formal;

- Elaborar uma sequência didática sobre o tema Botânica, por meio de vivências educativas que perpassam pelos espaços de educação formal e não formal;

- Validar a priori a sequência didática junto a pares.

\section{METOdOLOGIA}

A presente pesquisa foi desenvolvida baseada em uma abordagem qualitativa, neste contexto, os autores Bogdan e Biklen (1994) destacam cinco características da pesquisa qualitativa: (1) a fonte direta dos dados é o ambiente natural e o investigador é o principal agente na coleta desses mesmos dados; (2) os dados que o investigador recolhe são essencialmente de caráter descritivo; (3) os investigadores que utilizam metodologias qualitativas interessam-se mais pelo processo em si do que propriamente pelos resultados; (4) a análise dos dados é feita de forma indutiva; e (5) o investigador interessa-se, acima de tudo, por tentar compreender o significado que os participantes atribuem às suas experiências.

Para Bogdan e Biklen (1994, p. 287):

a abordagem qualitativa requer que os investigadores desenvolvam empatia para com as pessoas que fazem parte do estudo e que façam esforços concertados para compreender vários pontos de vista. O objetivo não é o juízo de valor; mas, o de compreender o mundo dos sujeitos e determinar como e com que critério eles o julgam.

Baseado nesses conceitos iniciais e nos objetivos deste trabalho, torna-se a mais adequada a escolha da abordagem qualitativa, do tipo estudo de caso, que será apoiada em diferentes técnicas de coleta de dados, realizadas pela pesquisadora ao longo do estudo, uma vez que pretende-se avaliar o processo durante a execução da 
sequência didática elaborada e o resultado final, com o intuito de compreender todo o processo de ensino e aprendizagem dos conteúdos botânicos ao longo das aulas programadas.

O desenvolvimento metodológico do tipo estudo de caso será realizado com base em Ludke e André (1986), para os quais, o desenvolvimento metodológico do tipo estudo de caso, possui as seguintes características: a) visa à descoberta; b) enfatiza a interpretação em contexto; c) retrata a realidade de forma completa e profunda; d) usa uma variedade de fontes de informação; e) permite generalizações naturalistas; f) procura representar as diferentes perspectivas presentes numa situação social; g) utiliza uma linguagem e uma forma mais acessível do que os outros relatórios de pesquisa.

O interesse do estudo de caso reflete no que ele tem de único, de particular, mesmo que, posteriormente, fiquem evidentes certas semelhanças com outros casos ou situações (LUDKE; ANDRÉ, 1986). De acordo com as autoras, esse tipo de estudo deve ser escolhido quando a pesquisa for algo singular, que tenha um valor em si mesmo. Esse tipo de pesquisa retrata a complexidade de uma situação particular, salientando o problema em seu aspecto total.

Sendo assim, foram definidos temas dentro do conteúdo programático de Botânica, para a elaboração da Sequência Didática (SD), o público alvo e de acordo com os temas escolhidos, os locais do Parque da Cidade que poderão ser utilizados, para a aplicação das aulas previstas na SD, conforme o Quadro 1.

Quadro 1: Público alvo, Temas e conteúdos de botânica abordados na SD. Fonte: Elaborado pela autora, (2018).

\begin{tabular}{|c|c|}
\hline $\begin{array}{c}\text { Público } \\
\text { Alvo }\end{array}$ & Temas e conteúdos de botânica \\
\hline & $\begin{array}{l}\text { Grupos Vegetais: } \\
\text { - Características evolutivas de Briófitas, Pteridófitas, Gimnospermas e } \\
\text { Angiospermas; - Reprodução por esporos; }\end{array}$ \\
\hline (1) $($ ) $@$ & \\
\hline
\end{tabular}




\begin{tabular}{|l|l|}
$\begin{array}{c}\text { 3o ano do } \begin{array}{c}\text { Ensino } \\
\text { Médio }\end{array} \\
\text { (angiospermas); - Comparativo evolutivo. }\end{array}$ & $\begin{array}{l}\text { - Reproduc̃a por Estróbilos (gimnospermas) e reprodução por flores } \\
\text { Tipos de frutos: } \\
\text { - Frutos verdadeiros, frutos partenocárpicos, pseudofrutos e infrutescências. }\end{array}$ \\
\cline { 2 - 2 } & $\begin{array}{l}\text { A importância das plantas medicinais. } \\
\text { - Plantas utilizadas como remédios naturais (hortelã, manjericão, maracujá, saião, } \\
\text { boldo, camomila). } \\
\text { - O uso das plantas em algumas culturas; } \\
\text { - A importância da cultura indígena, no uso das plantas, nos dias atuais. }\end{array}$ \\
\hline
\end{tabular}

Para Zabala (1998, p.18), a SD constitui-se de "um conjunto de atividades ordenadas, estruturadas e articuladas para a realização de certos objetivos educacionais". Sendo assim, a estrutura da SD será baseada no modelo metodológico da perspectiva dos três momentos pedagógicos de Delizoicov et al (2011), sendo os três momentos pedagógicos divididos em: Problematização, Organização do Conhecimento e Aplicação do conhecimento (DELIZOICOV et al, 2011).

Para Delizoicov (2011), o primeiro momento pedagógico consiste na Problematização inicial, onde são apresentadas aos alunos questões em que estes são desafiados a exporem seus pensamentos para que o professor tenha conhecimento dos mesmos. De acordo com Delizoicov (2011), este primeiro momento tem a finalidade de promover um distanciamento crítico do aluno com interpretações das situações apresentadas para discussão, promovendo a necessidade da aquisição de novos conhecimentos.

O segundo momento consiste na Organização do conhecimento, onde os conhecimentos necessários para a compreensão da problematização anterior são estudados. O terceiro e último momento pedagógico consiste na Aplicação do conhecimento, que visa abordar de forma sistemática o conhecimento que foi incorporado pelo aluno (DELIZOICOV et al, 2011). 
Posteriormente ao período de elaboração da SD, foi utilizada uma tabela de validação, segundo Guimarães e Giordan (2011), para a validação a priori da SD produzida a partir dos pressupostos propostos pelos autores, que será feita junto a pares. Para Guimarães e Giordan (2011), existem quatro categorias de análise desses pressupostos: Estrutura e Organização; Problematização; Conteúdos e Conceitos e Metodologias de Ensino e Avaliação.

Esse momento constituiu-se de muita relevância, pois os pares que participam puderam expor suas críticas sobre a SD proposta, a partir de suas experiências e alguns possíveis impasses que possam surgir durante o desenvolvimento prático da SD.

A validação da SD ocorreu no dia 14 de novembro de 2018, no Ifes - Campus, Vila Velha, tendo participado desse momento, 08 professores das redes municipal, privada, estadual e federal de ensino. Neste momento, houve uma prévia apresentação, onde a pesquisadora expôs a proposta da SD, com base nas aulas contidas na mesma. Logo após, os pares realizaram a avaliação escrita e comentada da SD.

De acordo com a análise realizada pelos pares, decidiu-se acatar a todas as considerações feitas pelos mesmos. A SD final, conta também com as sugestões propostas pela banca avaliadora deste trabalho.

\section{Potencialidades do PaRque da Cidade para o Ensino de Botânica}

O Parque da Cidade, situado entre os bairros Parque Residencial Laranjeiras e Valparaíso, na cidade de Serra, Espírito Santo, configura-se como um importante espaço com uma alta potencialidade educativa, para o ensino de botânica. O parque possui algumas áreas específicas, onde o professor pode desenvolver várias temáticas diferentes, com os alunos. 
Uma das áreas é a "Sala Verde" (Figura 1), que faz parte do Espaço Botânico, onde as visitas guiadas têm início. Nesse espaço, os alunos são acomodados, e o guia, que é o biólogo responsável pela administração do parque, faz um momento voltado para a Educação Ambiental. Os alunos são informados sobre a história do parque, sobre como devem se portar ao longo da visita, e sobre os espaços que visitarão.

Figura 1: Sala Verde. Fonte: Acervo próprio da autora (2018).

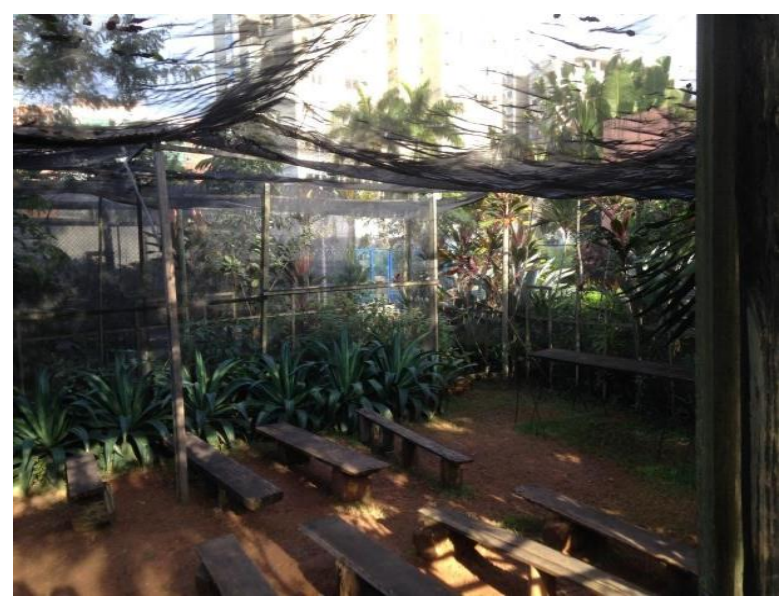

O Jardim Temático de Restinga, (Figura 2), possui um espaço que simula uma área com vegetação característica de restinga, como o próprio nome sugere. $\mathrm{O}$ ecossistema restinga compreende o conjunto de comunidades vegetais florísticas e fitofisionomicamente distintas, situadas em terrenos predominantemente arenosos formados, principalmente, durante as regressões e transgressões no nível do mar (Araújo \& Henriques 1984). O professor pode aproveitar este espaço para explicar que as comunidades vegetais encontradas nas restingas brasileiras são constituídas por espécies provenientes de ecossistemas como Mata Atlântica, Tabuleiros e Caatinga, que colonizaram essa faixa do litoral (Alves et al. 2007).

Figura 2: Jardim Temático de Restinga. Fonte: Acervo próprio da autora (2018). 


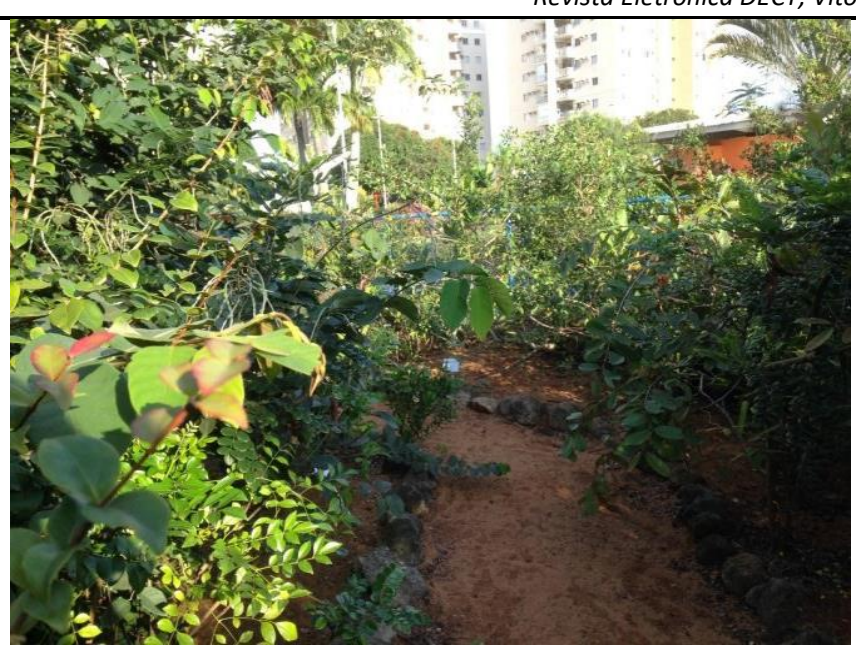

Outro espaço educativo, é a área destinada ao Orquidário (Figura 3) e ao Bromeliário (Figuras 4 e 5). Neste espaço, os alunos podem visualizar várias espécies de orquídeas e bromélias, e ainda, aprender sobre o modo de vida destas plantas, que muitas das vezes são confundidas com plantas parasitas, quando na verdade, são epífitas. As plantas epífitas são aquelas que possuem como habitat natural a superfície de outras plantas, sem absorver delas nutrientes ou água, portanto não são parasitas (MADISON, 1977). A visita a esses dois ambientes faz parte do circuito de Educação Ambiental, desenvolvido pelo próprio parque.

Figura 3: Orquidário Fonte: Acervo próprio da autora (2018). 


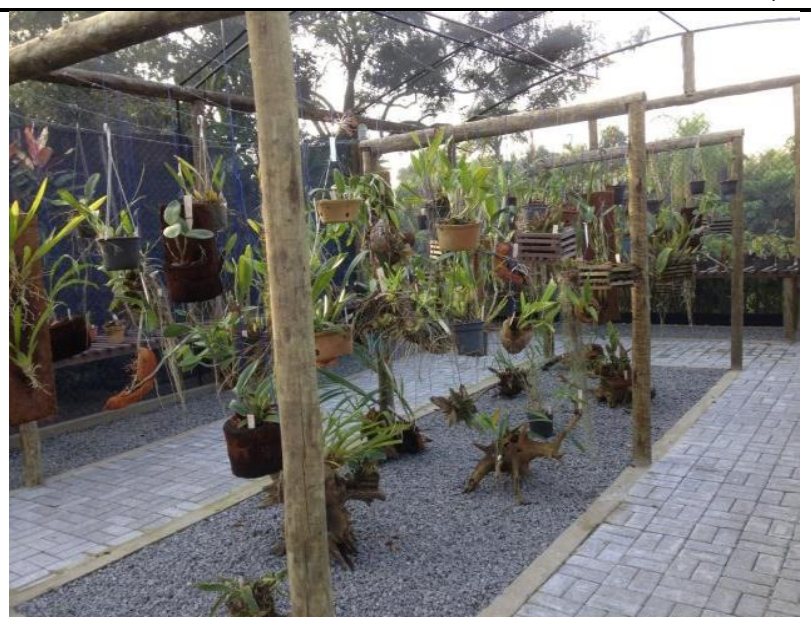

Figura 4: Bromeliário. Fonte: Acervo próprio da autora (2018).

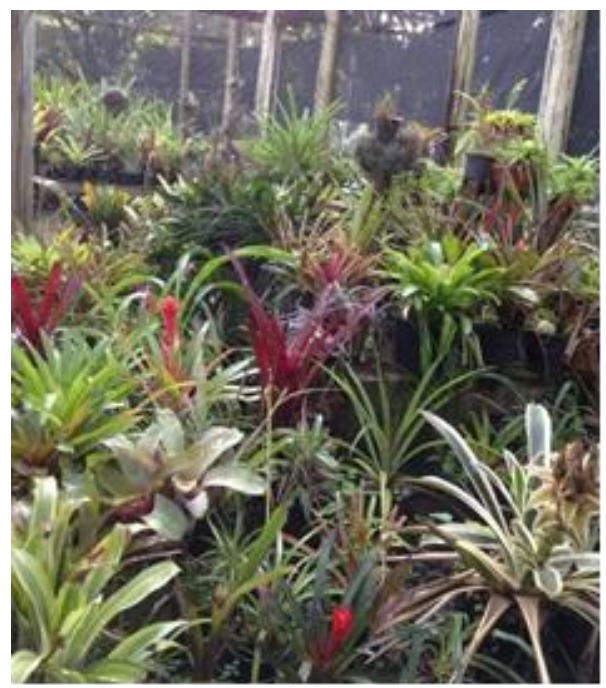

Figura 5: Bromélia. Fonte: Acervo próprio da autora (2018).

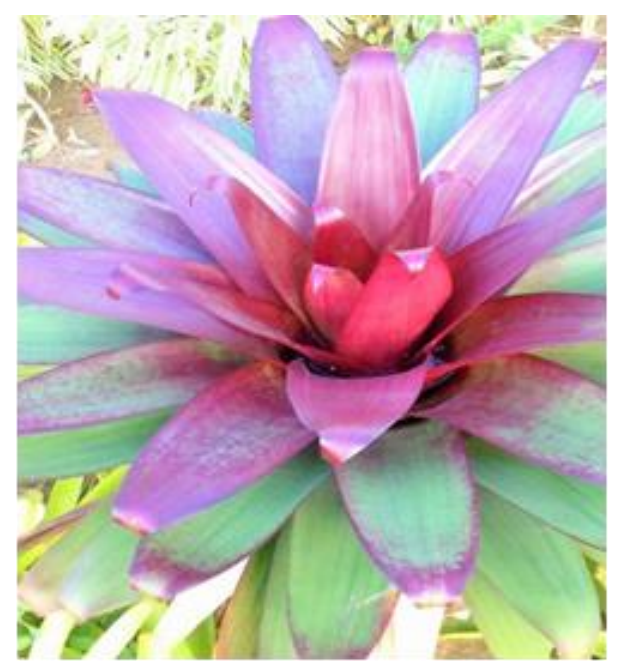


Todo o espaço do parque é ornamentado com vários tipos de plantas, que chamam muito a atenção, pela beleza, seja dos arbustos, das árvores ou das suas flores, como o Jasmim-manga (Figura 6), uma angiosperma comum em nosso estado, e de fácil cultivo, encontrada em vários locais. Ao longo da visita ao parque, é possível identificar representantes dos grupos vegetais (Briófitas, Pteridófitas, Gimnospermas e Angiospermas), estabelecendo as diferenças evolutivas entre eles, reforçando que várias linhas de pesquisa indicam que as plantas tenham se originado de alguns grupos antigos de algas verdes (RAVEN et al., 2007), e a importância de cada grupo.

Figura 6: Jasmim-manga. Fonte: Acervo próprio da autora (2018).

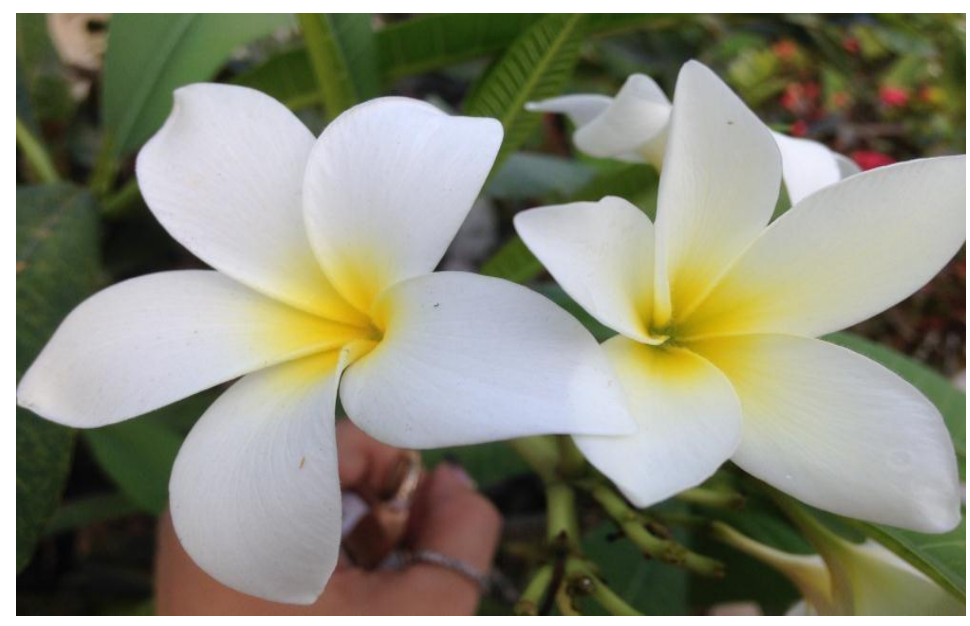

A área do Jardim Sensorial (Figura 7) é uma das mais atrativas e que proporciona uma experiência diferenciada para os alunos, pois os mesmos são orientados a retirarem os calçados, para entrarem neste espaço. A partir da percepção sensorial, os alunos têm contato direto, não só com o chão, mas também, com as plantas que possuem propriedades medicinais e características olfativas. Neste momento, os alunos são instigados a sentirem a textura das folhas, o cheiro das mesmas e a buscarem pela memória, se já tiveram algum tipo de contato, com alguma dessas plantas. 
O Jardim Sensorial possui plantas medicinais, como manjericão, alecrim, hortelã, camomila, carqueja, entre outras. Destaca-se aqui, a potencialidade educativa desse espaço, que permite que o professor aborde a temática das plantas medicinais, sua importância, além de incluir a abordagem sobre a origem da cultura de utilização das plantas, com o objetivo de se obter uma cura. Pode-se aproveitar esse espaço para um debate sobre a origem do uso das plantas nas culturas indígenas e africanas, por exemplo, e qual a importância dessa utilização até os dias de hoje. Além disso, o professor pode aproveitar para perguntar aos alunos seus familiares utilizam alguma planta específica, para tratar alguma doença, promovendo um momento de troca de experiências adquiridas a partir do convívio familiar.

Figura 7: Jardim Sensorial. Fonte: Acervo próprio da autora (2018).

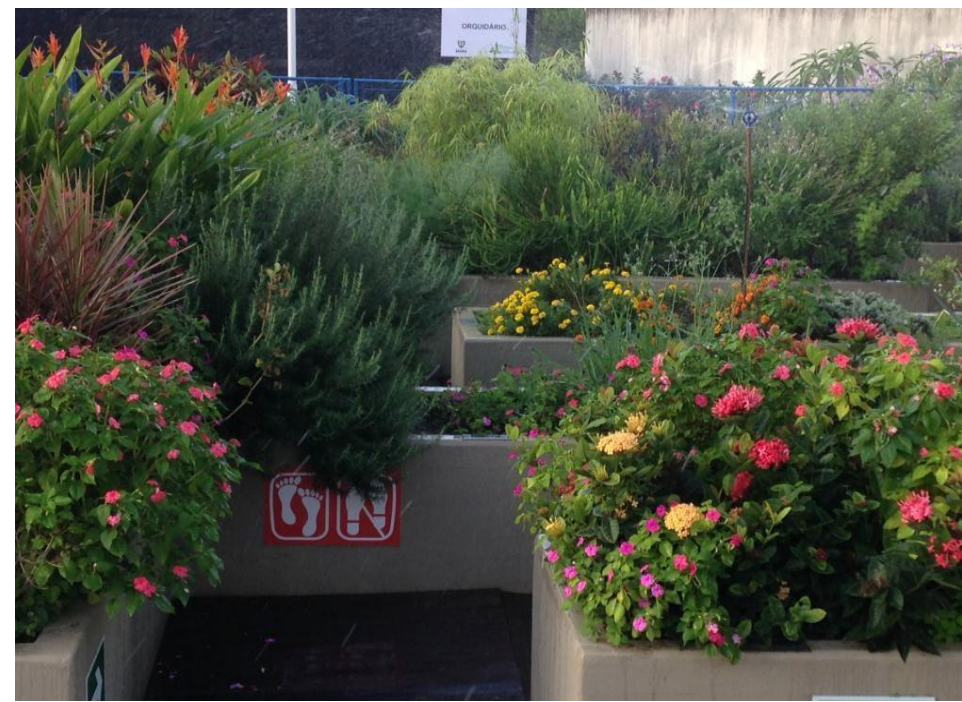

O circuito termina, com a visita dos alunos ao Viveiro de Mudas (Figura 8), o guia informa aos mesmos sobre como o Parque contribui para a preservação e reprodução de algumas espécies. O Parque da Cidade possui parcerias com várias instituições (privadas e públicas), com doações de mudas, para o incentivo do plantio de árvores, em diversos lugares do Espírito Santo. No viveiro de mudas, várias espécies frutíferas, como a Tangerina e o Araçá-Boi, ou ornamentais, são distribuídas gratuitamente, aos que participam da visita. Nesse momento, é possível explorar o contexto de 
preservação da natureza como um todo, a importância da recuperação de áreas que foram degradadas e a conscientização da importância do plantio de mudas.

Figura 8: Viveiro de Mudas. Fonte: Acervo próprio da autora (2018).

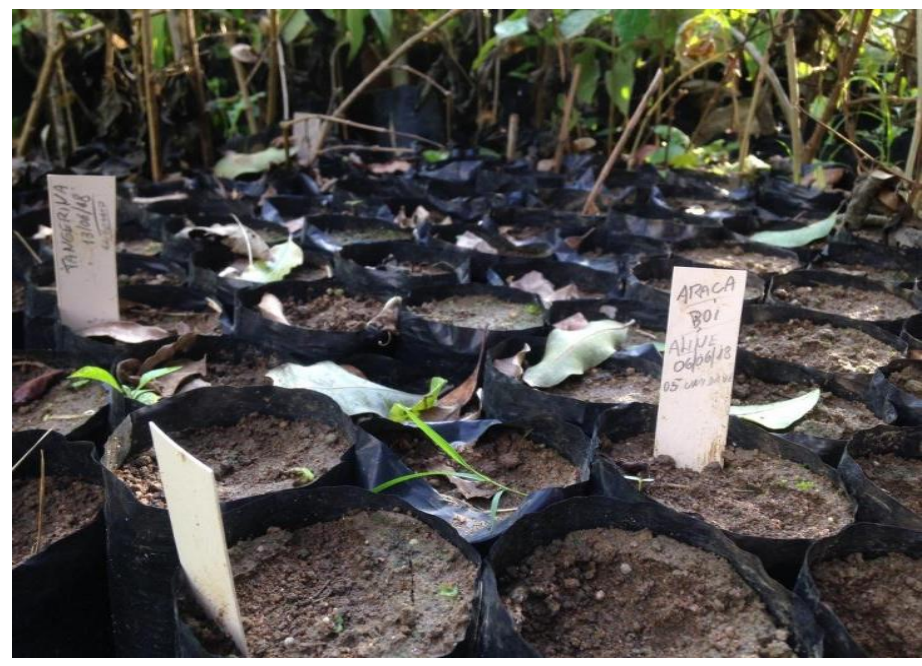

\section{PROPOSTA de SEQUÊNCIA DidÁtICA}

Após a definição do público alvo e de acordo com a análise do conteúdo programático de Botânica para o 3o ano do ensino médio, foi elaborada a proposta de SD intitulada "As plantas e o meu cotidiano". Apresenta-se a seguir (quadro 2), um resumo da proposta de SD, estruturada no quadro 1, assim como o seu detalhamento na mesma configuração que foi apresentada aos pares que participaram da validação a priori.

Para o primeiro momento pedagógico, problematização, a sugere-se uma visita ao Parque da Cidade, em Serra / ES, com o objetivo de proporcionar aos alunos o contato direto com um ambiente natural, além de reconhecer a importância de áreas de preservação em centros urbanos, despertando nos alunos o sentimento de pertencimento à Botânica. As atividades que compreendem o momento da problematização da SD, são baseadas em um registro fotográfico e anotações sobre os 
principais pontos da visita (jardim sensorial, jardim da restinga, orquidário,

bromeliário, viveiro de plantas, sala verde), que serão utilizados posteriormente, em uma atividade orientada pelo professor.

Quadro 3: Resumo da Sequência didática. Fonte: Elaborado pela autora, (2018).

\begin{tabular}{|c|c|c|}
\hline \multicolumn{3}{|c|}{ Sequência Didática: “As plantas e o meu cotidiano." } \\
\hline Etapas da sequência & Momentos & Atividades \\
\hline Problematização & 1 & $\begin{array}{l}\text { - Visita guiada ao Parque da Cidade, em Serra / ES; } \\
\text { - Registro fotográfico e anotações sobre os principais } \\
\text { pontos da visita (jardim sensorial, jardim da restinga, } \\
\text { orquidário, bromeliário, viveiro de plantas, sala verde). }\end{array}$ \\
\hline $\begin{array}{l}\text { Organização do } \\
\text { Conhecimento }\end{array}$ & $2,3,4$ e 5 & $\begin{array}{l}\text { - Aula expositiva com imagens através de slides } \\
\text { (incluindo fotos tiradas na visita ao parque); } \\
\text { - Visualização de representantes dos grupos vegetais (a } \\
\text { olho nu); } \\
\text { - Elaboração desenhos diferenciando os grupos } \\
\text { vegetais; } \\
\text { - Aula expositiva com imagens através de slides e fotos; } \\
\text { - Visualização das estruturas reprodutivas das plantas, } \\
\text { como flores, estróbilos e esporos e das sementes (a } \\
\text { olho nu); } \\
\text { - Piquenique em sala (ou no pátio) com a turma, } \\
\text { dialogando sobre os frutos trazidos para a aula, } \\
\text { identificando os diferentes tipos de frutos e } \\
\text { infrutescências presentes na alimentação do dia-a-dia; } \\
\text { - A partir da observação feita no jardim sensorial, } \\
\text { analisar as plantas conhecidas no cotidiano da turma, } \\
\text { associando-as com sua importância e eficácia; } \\
\text { - Atividade: investigar se na família há alguma receita } \\
\text { de remédio natural, utilizado ao longo das décadas. }\end{array}$ \\
\hline Aplicação do Conhecimento & 6 & $\begin{array}{l}\text { - Intervalo científico: } \\
\text { Os alunos farão uma exposição fotográfica, com os } \\
\text { registros realizados no parque. As fotos devem informar } \\
\text { na legenda a qual grupo vegetal as plantas pertencem. } \\
\text { Durante a exposição, ocorrerá a distribuição de chás e } \\
\text { receitas de remédios caseiros à base de plantas } \\
\text { medicinais e salada de frutas, e os alunos explicarão o } \\
\text { que aprenderam em sala. }\end{array}$ \\
\hline
\end{tabular}


Na etapa de Organização do Conhecimento (a partir do segundo momento), a sugestão é que o professor dê uma aula expositiva, utilizando recursos audiovisuais, para que através de imagens os alunos possam identificar e diferenciar as características evolutivas dos Grupos vegetais, iniciando pelos grupos de Briófitas e Pteridófitas, evidenciando as características evolutivas dos mesmos e a reprodução por esporos. Sugere-se que seja realizada uma dinâmica com os alunos, utilizando recursos como musgos (briófitas) e folhas de samambaias ou avencas (pteridófitas), para que os alunos vejam a olho nu, a diferença entre os indivíduos dos grupos. Para finalizar este momento, sugere-se que os alunos elaborem desenhos sobre as plantas que visualizaram durante a aula.

No terceiro momento da OC, sugere-se que o professor dê uma aula expositiva com imagens através de slides, para que os alunos possam aprender sobre as principais características dos grupos de Gimnospermas e Angiospermas, evidenciando as características evolutivas de cada grupo e o tipo de reprodução dos mesmos. Para a atividade, sugere-se que o professor leve para materiais para a visualização das estruturas reprodutivas das plantas, como estróbilos (gimnospermas) e flores (angiospermas), e se possível, das sementes. Desse modo, os alunos poderão ver a olho nu a diferença entre os grupos. Para finalizar este momento, sugere-se que os alunos elaborem desenhos sobre as plantas que visualizaram durante a aula.

No quarto momento da OC, a sugestão é a realização de um piquenique em sala (ou no pátio) com a turma, dialogando sobre os frutos trazidos para a aula, identificando os diferentes tipos de frutos, pseudofrutos e infrutescências presentes na alimentação do dia a dia. A proposta desse momento é proporcionar aos alunos, uma melhor fixação do conteúdo sobre os "frutos" consumidos no cotidiano, enquanto 
os mesmos podem socializar entre si, partilhando o lanche e podendo diferenciar um fruto de um pseudofruto ou de uma infrutescência.

Para o quinto momento da OC, sugere-se que partir da observação feita no jardim sensorial, os alunos analisem quais dessas plantas são conhecidas em seu cotidiano, associando-as com sua importância e eficácia. A atividade sugerida consiste em uma pesquisa, feita com os familiares, para descobrir se na família há alguma receita de remédio natural, utilizado ao longo das décadas.

Para conclusão da Sequência Didática, no sexto momento (aplicação do conhecimento), propõe-se um intervalo científico, onde os alunos farão uma exposição fotográfica, com os registros realizados no parque, para isso, as fotos devem informar na legenda a qual grupo vegetal as plantas pertencem. Outra sugestão, é que durante a exposição, ocorra a distribuição de chás e receitas de remédios caseiros, à base de plantas medicinais e também salada de frutas. Durante esse intervalo, os alunos explicarão o que aprenderam em sala.

\section{VALIDAÇÃo A PRIORI dA PROPOSTA de SEQUÊNCIA DIDÁtICA}

De acordo com o exposto na metodologia, a SD produzida foi validada a priori, por professores (pares), com base nos pressupostos propostos por Guimarães e Giordan (2011), que são formados por quatro categorias de análise: Estrutura e Organização, Problematização, Conteúdos e Conceitos e Metodologias de Ensino e Avaliação.

Os professores atribuíram um critério de suficiência, com intervalo de 1 a 5, para cada categoria avaliada. A partir da validação a priori feita pelos pares, foi possível aperfeiçoar a SD, com base nas críticas e sugestões feitas pelos mesmos.

Entendemos que o momento de validação da SD é muito importante e colaborativo, uma vez que os pares participam expondo suas críticas em relação à SD, 
contribuindo com suas experiências vividas em sala de aula, além de alertarem sobre alguns imprevistos que possam ocorrer durante o desenvolvimento das aulas propostas na sequência didática.

Para melhor compreensão da avaliação feita pelos professores, os mesmos foram nomeados aleatoriamente, de acordo com o alfabeto, sendo chamados de $A, B$, $C, D, E, F, G$ e $H$.

Vale ressaltar, que o instrumento de validação é preenchido com o nome dos professores, porém, para a tabulação dos dados, apresentados (a partir do quadro 4), preferimos não utilizar seus nomes próprios.

Em relação à ESTRUTURA E ORGANIZAÇÃO, a maioria dos tópicos recebeu dos pares valores de suficiência entre 4 e 5. O tópico A4.: "Referencial Teórico/ Bibliografia", recebeu de três professores, o valor de suficiência 3. As sugestões feitas a respeito desse tópico, ressaltam a importância de sugerir outras fontes bibliográficas, para uso do professor, que aplicará a SD:

Professor F: "A bibliografia deve ser mais variada, e não apenas a utilização do livro didático."

Professor G: "Utilize outras fontes de informação, além do livro didático."

A partir das observações feitas pelos professores " $F$ " e " $G$ " observa-se a preocupação com a bibliografia a ser utilizada, para o desenvolvimento da SD. Esse ponto é relevante pois, de acordo com a proposta da SD, vários materiais bibliográficos de apoio podem ser utilizados, enriquecendo o trabalho desenvolvido pelo professor.

Quanto à PROBLEMATIZAÇÃO, a maioria dos pares indicou um valor de suficiência igual a 4. No tópico B4., "Articulação entre os conceitos e a problematização e Contextualização de problema", os pares sugeriram que a problematização fosse voltada para perguntas, relacionadas à importância do Parque da Cidade, e à real importância do aprendizado dos alunos, em relação aos grupos vegetais. 
Professor B: "A problematização deve ser focada no aluno. Qual a importância de existir um parque, em um centro urbano? Qual a utilização das plantas no cotidiano dos alunos? Como os alunos associarão o conteúdo ao que for visto no parque?"

Professor C: "A problematização deve estar voltada para o aluno, e não para o professor."

Com relação aos CONTEÚDOS E CONCEITOS, a maioria dos itens foram avaliados com nota 5. Um dos professores, fez referência a utilização dos conhecimentos prévios dos alunos, que são valorizados ao longo da SD, inclusive, conceitos botânicos herdados pelas gerações, nas famílias.

Professor B: "Um ponto forte da sequência é o trabalho realizado com contextualização a partir do conhecimento coloquial."

Quanto ao tópico MÉTODO DE ENSINO E AVALIAÇÃO, a maioria dos itens foram avaliados com notas entre 4 e 5. O item D5., "Feedback de avaliação", teve notas divididas entre 3 e 4 . Foi sugerido um feedback mais diversificado, para saber dos alunos, como eles avaliaram as aulas aplicadas durante a proposta da SD.

Professor H: "Fazer o feedback diversificado com os alunos é importante, para saber como eles avaliaram todo o processo."

A validação a priori foi de suma importância para o desenvolvimento dessa pesquisa, caracterizando-se como um momento em que os pares puderam evidenciar detalhes que não tinham sido observados ao longo da construção do mesmo. Além disso, torna-se um momento riquíssimo, de troca de experiências entre os pares participantes.

Quadro 4: Resumo do Instrumento de Validação. Fonte: adaptado de Guimarães e Giordan, (2011).

\section{Validação a priori, realizada por pares:}


A - ESTRUTURA E ORGANIZAÇÃO

Atribuir um valor de suficiência quanto a coerência

A1. Qualidade e originalidade da SD e sua articulação com os temas da disciplina:

A2. Clareza e inteligibilidade da proposta:

A3. Adequação do tempo segundo as atividades propostas e sua executabilidade:

A4. Referencial Teórico/ Bibliografia:

\section{B- PROBLEMATIZAÇÃO}

Atribuir um valor de suficiência quanto a coerência

B1. O Problema:

B2. Coerência Interna da SD:

B3. A problemática nas perspectivas Social/Científica:

B4. Articulação entre os conceitos e a problematização:

B5. Contextualização de Problema:

B6. O problema e sua resolução:

\section{C - CONTEÚDOS E CONCEITOS}

Atribuir um valor de suficiência quanto a coerência

C1. Objetivos e Conteúdos:

C2. Conhecimentos Conceituais, Procedimentos e Atitudinais:

C3. Conhecimento Coloquial e Científico:

C4. Organização Encadeamento dos Conteúdos:

C5. Tema, Fenômeno, Conceitos:

\section{D - MÉTODO DE ENSINO E AVALIAÇÃO}

Atribuir um valor de suficiência quanto a coerência

D1. Aspectos Metodológicos:

D2. Organização das atividades e contextualização:

D3. Métodos de avaliação:

D4. Avaliação integradora:

D5. Feedback de Avaliação:

\section{OBSERVAÇÕES}

\section{CONSIDERAÇÕES FINAIS}

Esta pesquisa buscou contribuir para um melhor desempenho do professor, quanto ao ensino de botânica, visando o melhor aproveitamento e aprendizado do aluno, sobre tal conteúdo. Para isso, levantou-se o potencial educativo do Parque da Cidade, em Serra - ES, para o ensino de botânica na educação básica, na perspectiva da educação formal e não formal. 
A partir da escolha do espaço não-formal a ser utilizado, foram definidos temas dentro do conteúdo programático de Botânica, para a elaboração da Sequência Didática (SD), o público alvo, alunos do 3ํano do ensino médio e de acordo com os temas escolhidos, os locais do Parque da Cidade que poderão ser utilizados, para a aplicação das aulas previstas na SD.

A pesquisa foi elaborada de forma qualitativa, tendo como base, uma reflexão quanto ao ensino de botânica a partir do olhar presente na educação sociocultural freiriana, que traz pressupostos como a Educação Bancária x Educação Dialógica e Educação Crítica e Contextualizada (formação emancipatória do aluno).

Foi elaborada uma sequência didática sobre a disciplina Botânica, subdividindoa em tópicos para cada aula, por meio de vivências educativas que perpassam pelos espaços de educação formal e não formal, sendo que a mesma foi validada a priori, a junto a pares. As aulas foram propostas de acordo com conceitos que fazem parte do cotidiano do aluno, visando uma melhor interação entre o mesmo e as plantas. Os pares puderam opinar sobre a proposta de SD, sugerindo atividades e tecendo críticas construtivas, quanto à problemática, material didático de apoio e etc.

Todas as sugestões realizadas durante a validação a priori da SD, foram consideradas e a SD foi reformulada de acordo com as mesmas.

Espera-se contribuir para uma maior entrega e compromisso do professor, a partir a utilização da SD, nas aulas e também, uma melhor compreensão dos alunos, quanto ao conteúdo, de modo que consigam identificar a relação das plantas com o seu dia a dia.

Vale destacar que o ensino de botânica pode alcançar objetivos mais efetivos, se o professor buscar novas metodologias e se permitir conhecer novos instrumentos de ensino. Essa busca por novos estudos e melhorias nas suas práticas pedagógicas trarão 
resultados positivos para os alunos, que assimilarão o conteúdo, de forma a não o retirarem da mente, assim que as provas acabarem.

Sugere-se que novas pesquisas sejam realizadas, focadas no ensino de botânica, para que a essa área tenha mais bases teóricas, com o objetivo de auxiliar os professores dessa disciplina, e assim, os alunos serão altamente beneficiados. Com isso, além desta proposta de sequência didática, percebe-se que ainda temos muito a alcançar dentro do ensino de botânica, para isso, a pesquisadora te, como objetivo que essa pesquisa seja aprofundada e torne-se uma tese de especialização stricto sensu, utilizando novas tecnologias para o ensino de botânica.

\section{AGRADECIMENTOS}

Agradeço ao meu Deus, Criador de toda a natureza. Meu fiel consolador e provedor. Sem Ele, nada disso seria possível. A honra é Tua. Obrigada, Pai!

À minha família. Meus pais e minha irmã, minha base, meus motivadores. Obrigada por acreditarem em mim, por me incentivarem, por estarem ao meu lado incondicionalmente. Obrigada pela compreensão, por tanto amor, pelos momentos de descontração, necessários e muito valorizados. Vocês são parte fundamental nessa especialização.

Agradeço aos professores e à coordenação do curso de Especialização em Educação e Divulgação em Ciências, do Ifes - Campus Vila Velha, pelo aprendizado adquirido durante todo curso. Equipe maravilhosa!

Aos amigos do EDIV: Christyan, Danielle, Isabela e Vanessa Lamas. Vocês foram muito importantes durante esse processo. Obrigada por todos os momentos que compartilhamos! Que presente ter encontrado vocês!!

Agradeço especialmente à minha coordenadora, Manuella Amado. Querida, você é luz nesse mundo. Obrigada por tanto carinho com todos nós, por ser essa mulher que 
encanta a todos com sua garra, competência e amor a tudo o que faz. Que Deus continue abençoando os seus dias.

À minha amiga e orientadora Marina Cadete, por acreditar na minha ideia para este trabalho e por ter tido tanta paciência, ao longo do projeto. Obrigada, por literalmente segurar na minha mão e orar comigo. Gratidão pela sua vida.

Agradeço aos meus amigos, por compreenderem que a vida social de um pesquisador é cheia de "nãos", por me incentivarem e dividirem as alegrias e angústias dos momentos finais da realização dessa pesquisa.

Agradeço também a Prefeitura Municipal Serra, pela permissão para a parceria com o Parque da Cidade e consequente desenvolvimento desta pesquisa.

Por fim, agradeço a todos que contribuíram de alguma maneira, para esta pesquisa. Obrigado, de coração. 


\section{REFERÊNCIAS}

ALVES, R.J.V., CARDIN, L. \& KROFT, M.S. 2007. Angiosperm disjunction "campos rupestres restingas": a re-avaluation. Acta Botanica Brasilica, 21(3): 675-685.

ARAÚJO, D.S.D. \& HENRIQUES, R.P.B. 1984. Análise florística das restingas do estado do Rio de Janeiro. In: LACERDA, L.D., ARAÚJO, D.S.D., CERQUEIRA, R. \& TURCQ, B. (orgs.). Restingas, Origem, Estrutura e Processos. Niterói: Centro Editorial da Universidade Federal Fluminense. p. 327-342.

ARRUDA, S. M; LABURÚ, C. E. Considerações sobre a função do experimento no ensino de ciências. Ciência e Educação (UNESP), Baurú, v. 2, p.14-24, 1996.

BOGDAN, R. C.; BIKLEN, S. K.; Investigação qualitativa em educação: uma introdução à teoria e aos métodos. Porto: Porto Editora. 1994.

BITENCOURT, I. M. A botânica no ensino médio: análise de uma proposta didática baseada na abordagem CTS. Universidade Estadual do Sudoeste da Bahia, Jequié-BA. Programa de Pós-Graduação - Educação Científica e Formação de Professores (PPG.ECFP), 2013.

CECCANTINI, G. T. Os tecidos vegetais têm três dimensões. Revista Brasileira de Botânica, v.29, n.2, p.335-7, 2006.

DELIZOICOV, D.; ANGOTTI, J. A.; PERNAMBUCO, M. M. Ensino de ciências: fundamentos e métodos. 4a. ed. São Paulo: Cortez, 2011.

DIAS, M.C.P. O museu de ciências da vida como espaço de alfabetização científica: um olhar na formação continuada de professores. Programa de Pós-graduação em Educação em Ciências e Matemática, Instituto Federal do Espírito Santo, Vitória, 2014.

FARIA, R. L., JACOBUCCI, D. F. C., OLIVEIRA, R. C. Possibilidades de ensino de botânica em um espaço não-formal de educação na percepção de professoras de ciências. v.13. Rev. Ensaio. Belo Horizonte, n.01, p.87-104. Jan - Abr. 2011.

FERRAZ, M. H; FUSARI, M. R. Arte na educação escolar. 3.ed. São Paulo: Cortez, p.152, 1993.

FREIRE, P. Ação cultural para a liberdade. 5a ed., Rio de Janeiro: Paz e Terra, 1981.

FREIRE, P. \& SHOR, I. Medo e ousadia - o cotidiano do professor. Tradução de Adriana Lopez. Rio de Janeiro: Paz e Terra, 1986.

FREIRE, P. Pedagogia do oprimido. 17ạ ed. Rio de Janeiro. Ed. Paz e Terra, 1987.

FREIRE, P. A importância do ato de ler - em três artigos que se completam. São Paulo: Cortez, 1989.

FREIRE, P. Pedagogia da autonomia: saberes necessários à prática docente. Rio de Janeiro: Paz e Terra, 1996. 
GIANOTTO, D.E.P. et al. Elaboração e utilização de materiais pedagógicos de botânica e zoologia por professores de biologia. In: V EREBIO-SUL. Anais, São Paulo: SBenBio, 2011.

GOHN, M.G. Educação não-formal e cultura política: impactos sobre o associativismo do terceiro setor. São Paulo: Cortez, 1999.

GOHN, M. G. Educação não formal, participação da sociedade civil e estruturas colegiadas nas escolas. Ensaio: aval. pol. públ. Educ., Rio de Janeiro, v.14, n.50, 2006.

GOHN, M. G. Educação não formal e o educador social: atuação no desenvolvimento de projetos sociais. São Paulo: Cortez, 2010.

GOUVÊA, G.; LEAL, M. C. Alfabetização científica e tecnológica e os museus de ciência. In: GOUVÊA, G.; MARANDINO, M.; LEAL, M. C. (org.). Educação e museu: a construção social do caráter educativo dos museus de ciências. Rio de Janeiro: Acess, 2003.

GUIMARÃES, M.; VASCONCELLOS, M.M.N. Relações entre educação ambiental e educação em ciências na complementaridade dos espaços formais e não formais de educação. Educar em Revista, n.27, p.147-162, 2006.

GUIMARÃES, Y. A. F. E GIORDAN, M. Instrumento para construção e validação de sequências didáticas em um curso a distância de formação continuada de professores. VIII Encontro Nacional de Pesquisa em Educação em Ciências, 2011.

GULLICH, R.I.C.; ARAÚJO, M.C.P. Aspectos do ensino de botânica no currículo esboçado pela SBB. In: IV Seminário de Pesquisa em Educação da Região Sul - Florianópolis: UFSC/NUP, 2002.

HERSHEY, D. R. A historical perspective on problems in botany teaching. The American Biology Teacher, v.58, n.6, p.340-7, 1996.

JACOBUCCI, D. F. C. Contribuições dos espaços não-formais de educação para formação da cultura científica. Em Extensão, v. 7, p. 55-66, 2008.

KINOSHITA, L.S.; TORRES, R.B.; TAMASHIRO, J.Y.; FORNI-MARTINS, E.R. (2006). A botânica no ensino básico: relatos de uma experiência transformadora. São Carlos: RiMa.

KLEIN, E.S.; PINHEIRO, M.A.M.; SILVEIRA, V.C.; LIMA, M.S.B.; TORRES, R.B.; KINOSHITA, L. S. (2001). Construindo o conhecimento de botânica: uma experiência interdisciplinar em campinas. Ciência \& Ensino, n. 10, p. 9-13.

KRASILCHIK, M., TRIVELATO, S. L. F. Biologia para o cidadão do século XXI: 1o parte. São Paulo, FE - USP, CAPES/PADCT, p. 26, 1995.

KRASILCHIK, M. Ensino de ciências e cidadania. São Paulo: Moderna, 2004. 
KRASILCHIK, M.; MARANDINO, M. Ensino de ciências e cidadania. São Paulo: Moderna, 2007.

KRAUZER, K. A. F. Projeto escolar de botânica sob a perspectiva da abordagem ctsa: uma estratégia para promover a aprendizagem significativa crítica no ensino médio. Programa de Pós-graduação em Educação em Ciências e Matemática. Instituto Federal do Espírito Santo. Vitória - Espírito Santo, 2014.

LUDKE, M.; ANDRE, M. E. D. A. Pesquisa em educação: abordagens qualitativas. São Paulo: EPU, 1986.

MACEDO, M. et al. Concepções de professores de biologia do ensino médio sobre o ensino-aprendizagem de botânica. In: Encontro Ibero-americano sobre Investigação em Ensino de Ciências, 2012, Porto Alegre. Anais, 2012.

MADISON, M. Vascular epiphytes: their systematic occurrence and salient features. Selbyana, v. 2, n. 1, p.1-13, 1977.

MARANDINO, M. Educação em museus: a mediação em foco. São Paulo: FEUSP, 2008.

Parque da cidade na serra será ampliado. Disponível em: <http://gvnews.com.br/parque-dacidade-na-serra-sera-ampliado/> Acesso em: 17 jun. 2018.

PINTO, A. V. Importância das aulas práticas na disciplina de botânica. CASCAVEL- FAG, 2009.

RAVEN, P. H., EVERT, R. F. \& EICHHORN, S. E. Biologia vegetal, 7. ed. Rio de Janeiro: Guanabara Koogan, 2007.

SANTOS, D. Y. A. C., CHOW, F., FURLAN, C. M. A botânica no cotidiano. Ensino de

Botânica - Curso de atualização de professores de Educação Básica. São Paulo, 2008.

SANTOS, D. Y. A. C. et al. A botânica no cotidiano. Ribeirão Preto: Holos Editora, 2012.

SANTOS, I. C. O.; SILVA, B. I.; ECHALAR, A. D. L. F. Percepções dos alunos do curso de biologia a respeito de sua formação para e com o conteúdo de botânica. In: VI EDIPE Encontro Estadual de Didática e Práticas de Ensino, 2015, Goiânia. VI EDIPE: Organismos internacionais, currículo e didática. Goiânia: CEPED, 2015 a.

SANTOS, M. L.; Oliveira, R.R.S.; MIRANDA, S. C.; RAMOS, M. V. V. O ensino de botânica na formação inicial de professores em instituições de ensino superior públicas no estado de Goiás. In: X Encontro Nacional de Pesquisa em Educação em Ciências, X ENPEC, 2015, Águas de Lindóia. Anais do X ENPEC. Águas de Lindóia: ABRAPEC, p. 1- 8, $2015 b$. SARTIN, R.D. et al. Análise do conteúdo de botânica no livro didático e a formação de professores. In: IV ENEBIO, 2012, Goiânia. Anais. SBenBIO, 2012. 
SEABRA, L. A. F. et al. A utilização da metodologia de investigação no ensino de botânica: superando limitações de formação. In: X Fórum Ambiental da Alta Paulista, 2014, Anais. 2014.

SILVA, L. M.; CAVALLET, V. J. ALQUINI, Y. O professor, o aluno e o conteúdo no ensino de botânica. Revista Santa Maria, v. 31 - n. 01, p. 67-80, 2006.

SILVA, P. G. P. O ensino da botânica no nível fundamental: um enfoque nos procedimentos metodológicos. Tese (Doutorado em Educação para a Ciência). Universidade Estadual Paulista Júlio de Mesquita Filho, UNESP, 2008.

SILVA, G.P.N.; SOUZA, L.M.; O ensino de botânica na educação fundamental ii: análise de uma proposta educativa. IX Congreso Internacional sobre Investigación en Didáctica de las Ciencias. Revista Electrónica de Enseñanza de las Ciencias. Girona, Espanha, 2013.

SILVA, J. N.; GHILARDI-LOPES, N. P. Botânica no ensino fundamental: diagnósticos de dificuldades no ensino e da percepção e representação da biodiversidade vegetal por estudantes de escolas da região metropolitana de São Paulo. Revista Electrónica de Enseñanza de las Ciencias, v.13, n.2, p.115-36. 2014.

SOUZA, A. L. S., CHAPANI, D. T. Teoria crítica de Paulo Freire, formação docente e o ensino de ciências nos anos iniciais de escolaridade. Rev. Lusófona de Educação [online]. 2013, n.25, pp.119-133. ISSN 1645-7250.

TOWATA, N. et al.; URSI, S.; SANTOS, D. Y. A. C. Análise da percepção dos licenciandos sobre o „ensino de botânica na educação básica”. Revista da SBenBio. n.03, p.: 16031612, 2010.

TRILLA, J.; GHANEM, E.; ARANTES, V. A. Educação formal e não-formal: pontos e contrapontos. São Paulo: Summus, 2008.

URSI, S.; BARBOSA, P.P.; SANO, P.T.; BERCHEZ, F.A.S. Ensino de botânica: conhecimento $e$ encantamento na educação científica. Estudos avançados. Ensino de Ciências. Instituto de Biociências, Universidade de São Paulo, São Paulo, Brasil, 2018.

ZABALA, A. A prática educativa: como ensinar. Porto Alegre: Editora Artes Médicas Sul Ltda., 1998. 